and spleen in a small boy after his chronic post-pneumonic empyema had been closed by thoracoplasty. Sherlock (1945), by liver biopsy in a case of chronic diarrhoea due to an unexplained ileo-sigmoid fistula, found that after two years her patient had gained weight despite continued moderate diarrhoea, and that his amyloid infiltration was considerably "less coarse."

Liver therapy cannot be said to have benefited any of these cases, though it was given during convalescence by Rosenblatt, but in the cases of Trasoff et al. (1944) and of Kennedy (1935) it may have had some good effect.

\section{Summary and Conclusions}

Two cases of rheumatoid arthritis complicated by amyloid disease have been described. Although there is uncertainty about the mode of production of this disease, it is noteworthy that in both cases the rheumatoid condition had been protracted and had caused pronounced wasting and anaemia as well as crippling joint changes.

In one case the disease had brought about blood-protein changes, only partly attributable to the severe associated albuminuria.

It is suggested that the amyloid-tissue changes are not due to the blood-protein changes, but that both are attributable to the rheumatoid infection.

Each case had had moderate gold therapy, but this probably had no bearing on the development of amyloidosis.

It is noted that one case, in spite of gross hepatic enlargement, splenomegaly, and marked albuminuria, shows no deterioration. The other patient died in uraemia, the only way in which amyloid disease can directly cause death.

Where the liver is enlarged, liver biopsy may be used with safety to establish the diagnosis.

Treatment with whole liver extract has so far had no definite effect on the amyloid deposits.

It is suggested that secondary amyloidosis is dispersed only after cure of the primary complaint.

It will be interesting to observe the effect of cortisone on the amyloid changes due to rheumatoid arthritis.

I am indebted to Dr. K. M. Lawther, of Middlesex Hospital, for details of the early course of the illness in Case 2, and to my colleague, Dr. L. I. M. Castleden, for the later notes on the same case. I am grateful to Dr. J. L. Hamilton-Paterson for help with the investigations and histology in these two cases, to Miss $\mathbf{M}$. $\mathbf{H}$. Shaw for the preparation of the photomicrographs and the photograph of Case 1, and to Dr. G. M. Barrett for the liver biopsy specimen from the same case.

\section{REFERENCES}

Baber, M. D. (1947). Lancet, 1, 210

Beattie, J. M. (1906). British Medical Journal, 2, 1444.

Boyd, W. (1947). Textbook of Pathology, 5th ed.,. p. 29. London Butt, E. M. (1930). Arch. Path., 10, 859.

Carroll, J. H., and Nelson, R. L. (1927). Arch. Pediat., 44, 187.

Eagles, G. H., Evans, P. R., Fisher, A. G. T., and Keith, J. D. (1937). Lancet, $2,421$.

Findley, J. W., and Adams, W. (1948). Arch. intern. Med., 81, 342. Goldthwait, J. E. (1940). New Engl. J. Med., 223, 568.

Gordon, M. H. (1948). Lancet, 1, 697.

Hill, L. C. (1948). Proc. R. Soc. Med., 41, 607.

Imrie, A. H., and Aitkenhead, A. C. (1939). Lancet, 2, 421.

Kennedy, W.' R. (1935). Canad. med. Ass. J., 33, 385 .

Langstein, L., and Mayer, M. (1903). Beitr. chem. Physiol. Path. 5, 69.

Lush, B., Chalmers, I. S., and Fletcher, E. (1948). Ann. rheum. Dis., 7, 225.

Reimann, H. A., and Eklund, C. M. (1935). Amer. J. med. Sci. $190,88$.

Koucky, R. F., and Eklund, C. M. (1935). Amer. J. Path., 11 977.

Rosenblatt, M. B. (1933). Amer. J. med. Sci., 186, 558.

(1936). Arch. intern Med., 57, 562.

Sherlock, S. (1945). Lancet, 2, 397.

Trasoff, A., Schneeberg, N., and Scarf, M. (1944). Arch. intern. Med., 74, 4.

Walker, G. F. (1928). Lancet, 2, 120

Warren, S. (1930). Amer. J. Path., 6, 161.

Whitman, R. (1903). Med. Rec., 63, 601.

Yeoman, W., and Wilson, J. V. (1947). British Medical Journal, 2, 483 .

\section{MEDICAL ADMINISTRATION IN THE TROPICS}

\author{
BY
}

GeORGe MACleAN, C.B.E., M.B., Ch.B.

Formerly Deputy Director of Medical Services in Tanganyika Territory, and Director of Medical Services, Trinidad and Tobago

Medical administration in the Tropics presents certain special features of its own. The climate, the prevalence of debilitating and often fatal communicable diseases, the effects on health and social life generally of economic development on the one hand or economic stagnation on the other, and, in many instances, the customs and beliefs of the general population in regard to diseases and their causation, all combine to produce conditions which differ in many important respects from those met in the more organized countries of temperate climates.

The situation in Tanganyika Territory after the 1914-18 war serves to illustrate the problems which face a medical service dealing with primitive conditions, while that in Trinidad and Tobago, with well-organized industries and more than a century of medical services, provides examples of the problems met in a comparatively advanced country.

\section{Health Conditions and Medical Services in Tanganyika Territory}

When the British took over the administration of German East Africa, as Tanganyika Territory was then, the effects of war were so devastating that, though some hospitals and laboratories were available and a number of trained dressers still remained, such medical services as the German Government had developed had almost completely disintegrated. The war was followed by a pandemic of influenza and by extensive famines.

As the British civil administration replaced the military occupation a medical department was gradually built up. But even in 1921 a medical officer, assisted by a few sub. assistant surgeons, compounders, and dressers, might find himself responsible for the public health of a quarter of a million people, or even (though rarely) half a million. Such a service could touch only a fraction of the population, and indigenous forms of medicine and public health were widely practised. How effective the herbal remedies were it was hard to assess. It was rarely possible for an outside observer to study individual patients who were under treatment, and even more difficult to get to knou the remedy used, as the "trade secrets" were closely guarded. For example, claims of success were made in the treatment of gonococcal infections, and there were apparently some grounds for the claims.

The abandonment of a house after one or more deaths had taken place in it seems to have been a common practice, and there may have been occasions when the custom was of benefit as a public health measure. The circumstances in which I saw the abandonment of houses most in evidence were during a sleeping-sickness epidemic, and the consequences were the opposite of salutary in that the effect was to spread the disease over thousands of square miles. Variolation was another common practice, and it is not improbable that it contributed to the dissemination of infection.

Witchcraft played its part in the sphere of health. It was, for example, apparently believed over a wide area 
that leprosy was transmissible either by heredity or by means of witchcraft. Contact with a leprous case, no matter how close and continuous, was therefore not feared. It can easily be seen how such a belief would interfere with any measures of leprosy control. An even more sinister form of witchcraft manifested itself when it was believed that the death of a person was the work of an enemy practising witchcraft. When the guilty person was " discovered" it became a public duty to destroy him (or her). A number of known murders, even in recent years, were committed as a "public duty" of this nature.

\section{The Medical Department}

It was among beliefs and practices of this kind, differing in detail in different areas, that a medical officer carried on his work in the early days of the British administration. The medical department of that time consisted of a headquarters, a laboratory service, a central medical store, a number of station units, one or two medical officers for town and port work, and a dental officer.

The headquarters staff comprised a principal medical officer (a designation afterwards changed to director of medical services), a deputy principal medical officer (afterwards changed to deputy director of medical services), a senior sanitation officer (afterwards changed to deputy director of sanitary services), and their clerical staff. Early in the history of the department the principal medical officer became, ex officio, a member of the Executive and Legislative Councils. In addition to these and various other duties he also became President of the Medical Registration Board and Chairman of the Central Town Planning and Building Committee. This committee was given statutory powers to regulate building in townships. In the districts the Central Committee was represented by subordinate committees, the medical department's representative on them being the station medical officer or medical officer of health.

The laboratory service carried out public health bacteriology (including. water sampling), clinical pathology, medico-legal work, and the production of various vaccines. There was no chemist attached in the first instance, but a chemistry section was added later.

The central medical store was the distributing unit for medical supplies.

The station units were the basic units of the department. One unit was usually under the direction of a medical officer (the station medical officer), who was assisted by one or more sub-assistant surgeons, and by compounders and dressers. Some of the more important units were placed under senior medical officers, and there were a number of sub-units, usually subordinate to the medical officer or senior medical officer of a full unit, which were placed under sub-assistant surgeons, compounders, or dressers. The head of a station unit was directly responsible to the Principal Medical Officer. The unit headquarters were always, or nearly always, at the administrative headquarters of a district. The medical officer was usually given a small station hospital to work, and he conducted, in the station and in the district, such sanitary and other public health activities as he was able to undertake. One of the simplest of these-because it could be carried out by dressers and other subordinate staff-and one of the most important, was vaccination against smallpox.

\section{Problems of Administration}

In the early days of the administration little systematic survey work could be done, but the Service was able to get some indications of the problems with which it had to deal from the records of work carried out by the former German administration, from cases observed at the station hospitals, from the sanitary conditions found in the stations themselves and in places visited outside them by the medical officers, and from reports received through district administrations, chiefs, and other persons. It was found that helminthic diseases, malaria, relapsing fever, and venereal diseases (following in the wake of trade and war) were widespread; the dysenteries, leprosy, schistosomiasis, tropical ulcer, yaws, and many of the general diseases were common ; anthrax, sleeping sickness, smallpox, tuberculosis, and sometimes plague (bubonic) occurred in places. At the end of 1921 there were 23 station medical officers (including senior medical officers and medical officers of health) and 21 sub-assistant surgeons, with their ancillary staffs, to deal with this assortment of diseases in a country over 350,000 square miles in extent ; moreover, the mental attitude of the general population towards the various conditions complicated the work. The few mission and private practitioners in the country concerned themselves almost entirely with individual cases, except that some missions gave considerable assistance in looking after leprosy settlements.

The central administration was able to give some direction on policy and on specific public health measures and to carry out a limited amount of inspection, but the medical officers, especially in the more remote districts, had to rely largely on their own initiative and judgment. This organization, while allowing scope for initiative, militated against the development of co-ordinated public health policy-all the more so as medical officers might serve for no more than two to two and a half years consecutively in the one station. This weakness was partly eliminated by the formation of special units, and, later, by the introduction of a provincial system of medical administration. The first special unit to be formed was the sleeping-sickness control branch, which began work in 1926 . The necessity for this branch arose from the fact that Rhodesian sleeping sickness had, for the first time on record, now appeared in epidemic form. One of the features of this unit was the opportunities which it provided for interdepartmental collaboration. People had to be settled on new land, usually in tsetse bush, and problems relating to native beliefs and customs (provision had sometimes to be made even for the transfer of an ancestral spirit), district administration, and agriculture were nearly always involved, and the Department of Geological Survey had sometimes to be consulted on water supplies.

Later on, research units for sleeping sickness (distinct from the executive unit), malaria, and tuberculosis were formed. They all proved valuable to the Service because of the investigations which they were able to undertake and the guidance they were able to give to medical officers and medical officers of health. Special interest attaches to the work of the sleeping-sickness research unit, which showed that the trypanosome of Rhodesian sleeping sickness could pass from man through tsetse, game animal, and again through tsetse, and remain infective to man (Corson, 1935). The possibility of this cycle taking place could be shown only by experiments on human volunteers, the first of whom was the experimenter himself.

Other units of a different kind which were formed included an institute for the production of calf-lymph smallpox vaccine, and a training school for dispensers, who, in addition to dispensing, were taught the diagnosis (including microscopical diagnosis) and treatment of some common diseases.

The introduction of a provincial medical administration was necessarily preceded by the formation (in 1925-6) of provinces, in each of which the provincial commissioner was the representative of the central Government. In the provinces there were native authorities, responsible to the provincial commissioner and his district officers, 
who administered native law and customs within certain prescribed limits.

The provincial medical officers, when their posts were created about ten years after the formation of provinces, administered the medical and public health services in these provinces. They were the responsible advisers to the provincial commissioners on health matters, but were directly responsible to the Director of Medical Services in both technical and administrative matters.

The rudiments of a Native Authorities' medical service came into being with the introduction of tribal dressers. These dressers were trained in the Government hospitals, but after training came under the administration of their own Native Authorities, though Government medical officers gave them a certain amount of supervision in an advisory capacity. Their standard of efficiency was very low at first, but they were the beginning of a service which may eventually be a useful one under local governments.

The dental service remained a branch of the medical department throughout, but even in 1938 it was still limited to two regular officers and a dental mechanic.

This review of the Tanganyika medical administration covers the period up to 1938 only. During these years the declared policy of the medical department was virtually controlled by the Director, subject only to the limitations set by finance and to the provisions of infectious diseases and other relative ordinances. He continued to preside over the Board responsible for the registration and professional discipline of medical practitioners, and the members of the Board were, in practice, nominated by him. He ceased to be an ex officio member of the Executive Council, but continued on the council as a nominated member, and also continued to be a member of the Legislative Council. He had his own staff, administrative and executive (including, by now, specialists in medicine and surgery), available to advise him, but there was no standing advisory committee or board of health to advise or assist him.

Fuller information on the organization of the medical department may be obtained from its annual reports and from the ordinances relating to public health and town planning and building.

\section{Medical Administration in Trinidad and Tobago}

Medical administration in Trinidad and Tobago has undergone considerable changes since the inception of medical services in these islands. An interesting history of those services, covering a period of 130 years, has recently been written by Dr. Roul Seheult (1948), a former resident surgeon of the Colonial Hospital, Port of Spain.

The administrative system as it was in 1947 consisted of certain statutory bodies which were responsible for the administration of laws relating to public health and to the professions of medicine, dentistry, pharmacy, and midwifery; of a health department of the central Government; and of certain health services provided by municipalities.

The chief statutory bodies are the Central Board of Health; the local health authorities, which are subordinate to the Central Board of Health; and the Medical Board of Trinidad. There is also an advisory committee, not a statutory body, which advises the Director on matters of policy.

The functions, powers, and the duties of the Central Board of Health are laid down in the Public Hea!th Ordinance of Trinidad and Tobago. The Board has wide powers for the control of infectious diseases; it can frame model by-laws, approve or refer back for revision any by-laws submitted by a local health authority; and it has discretionary powers in respect of the erection of and repairs to buildings. The by-laws framed or approved by the Board must receive the approval of the Governor in Council and be published in the Royal Gazette of the Government before they come into force. The Director of Medical Services is, ex officio, chairman of the Board ; its members, who are partly official and partly non-official, are appointed by the Governor.

The local health authorities are, under the Board. responsible for their respective areas, which correspond to the different administrative units-municipality or count! - of the Colony. In the municipalities (city or county. as the case may be) the council, an elected body, comprises the local health authority. In the counties the chair. man and members were up to 1947 appointed by the Governor.

The local health authorities may prepare by-laws and submit them for approval to the Central Board of Health They are responsible for seeing that the Public Health Ordinance and the by-laws made under it are complied with. They grant certain licences and issue certain permits, and they exercise such special powers as may be delegated to them by the Central Board of Health.

In the city of Port of Spain, the city council, which is also the local health authority, has its own medical officer of health and sanitary staff. The medical officer of health is not in this case responsible to the Director of Medical Services except in so far as the local health authority to which he is the expert adviser on public health matters is responsible to the Central Board of Health, of which the Director is chairman. In the case of the borough councils the medical officers of health are seconded from the Health Department of the central Government and, though directly responsible to the borough councils for administrative purposes, they remain under the technical direction of the Director of Medical Services. In the counties the medical officers of health are responsible to the Director of Medical Services or his local representatives in both administrative and technical matters.

The Medical Board of Trinidad has its functions, duties. and powers laid down in the Medical Board Ordinance. It is composed of all the registered medical practitioners of the Colony, and its council, appointed by the members from among themselves, is responsible for the professional discipline of members of the professions of medicine, dentistry, pharmacy, and midwifery. It also provides for the registration of medical and dental practitioners; it conducts examinations for, issues licences to, and registers candidates for the three other professions; and it has certain other duties.

The present functions of the Health Department are not defined by statute or by Government regulation except to a very limited extent (e.g., the Director and some members of his staff have certain ex officio duties), though these functions are largely a growth from the early obligations undertaken by the Government to provide medical care for the indigent and to control acute infectious diseases.

Its organization consists of a headquarters and a number of units, each of which is directly responsible to the Director. The main units are the county health services; the specialist units comprised by the leprosy, malaria, tuberculosis, and venereal diseases divisions ; the general hospitals, providing specialists in medicine, surgery, and midwifery, with radiology and radiotherapy in some; the houses of refuge (combinations of workhouses and infirmaries for chronic indigent cases); the central laboratory, carrying out clinical 
pathology, public health bacteriology, and the production of vaccines; the central medical stores; and the dental service.

The county health services are the basic units of the department. As these units are designed, each county should have its own separate service, but shortage of staff has necessitated the placing, in some cases, of several counties under a senior medical officer of health. County health work groups itself into five main categories-namely, advice on town and village planning; the control of communicable diseases, where this is not undertaken by specialist units ; medico-legal services ; family welfare services, especially maternity and child welfare, school medical services, nutrition, and health education ; and services for general diseases and injuries, including, in some places, in-patient treatment. Some services, like applied health education, are still in their infancy, and some, like the school medical service, are still inadequate. The counties do not have their own specialist services. Cases requiring medical or surgical specialist treatment are sent to the general hospitals, and the specialist units deal with major problems in their particular specialty.

This review of medical administration in Trinidad and Tobago refers to conditions as they were in 1947. It will be seen that organized unofficial responsibility in matters of public health and professional discipline had proceeded there much further than it had in Tanganyika Territory just before the 1939-45 war. The Colony of Trinidad and Tobago had also relatively a much larger staff. At the end of 1946 its establishment of registered medical practitioners in the health department, including specialists and officers carrying out administrative duties, was 101 (though actually a large number of posts were vacant), whereas at the beginning of 1939 , in Tanganyika Territory with a population of about $5,500,000$-more than eight times that of Trinidad and Tobago-the establishment of registered medical practitioners was 50 , and of the various grades of assistant and sub-assistant surgeons 55. Besides, probably there were relatively more private practitioners in Trinidad and Tobago than in Tanganyika.

\section{Present-day Trends and Needs}

The changes that are taking place in the outlook and modes of living of tropical peoples, the expansion and increasing complexities of social services, and, in some countries at least, the growth of representative government have all produced a tangle of trends and needs which complicate the duties and problems of medical administration and call for new orientations.

If the growing demands for satisfactory standards of health and the growing readiness to provide the means are to be implemented the general population must be taught the parts which they have to play in order to attain them, and their representatives and leaders must learn the principles and the liabilities involved. Medical administrators themselves should be selected early in their careers and given facilities for special training; and there must be adequate direction and control.

The training of any people on a large scale in healthy living and health discipline is not an easy undertaking. The task of disseminating health education which will be of practical value in primitive communities is a gigantic one, and the time and continuity of effort required to make a success of it can be appreciated only by learning something of the deep-rooted traditional beliefs which exist in tropical countries about the causation and significance of disease. These beliefs have to be replaced by genuine knowledge, and the old customs which are not compatible with it replaced by new habits and standards of living. It is a problem which has to be faced, and it is by no means a hopeless one. The main objectives are definite enough: the blending of health habits and attitudes with day-to-day activities ; the imparting of such knowledge and the inculcation of such sense of responsibility as may be necessary for healthy living in a way in which their application to everyday life may be understood and practised; and the healthy cultivation, or at least the maintenance, of the primitive faculty of intuitive interpretation of bodily symptoms-a necessary safeguard against the hypochondriasis which may follow on a misguided interest in disease.

Even among the more sophisticated, who might be expected to be the interpreters of health education to their simpler neighbours, there are obvious difficulties in the case of people with traditions which are quite alien to our own. There are, for instance, the contradictions in the teaching given in the semi-pagan home or neighbourhood and that given in schools and clinics ; and conflicts, which may even lead to neuroses, may develop where religious teaching is at variance with current opinions and practices. For this and other reasons, as life in the Tropics becomes more complex so the practical aspects of the neuroses are likely to become more apparent. They are responsible for a large amount of invaliding now among the more sophisti-cated and less stable communities, and it may well be that medical administrations will have to give as much attention to their general predisposing causes as they now do to the control of communicable diseases. (If is not only in the subconscious minds of patients that conflicts ma! take place. The role of the medical administrator may be particularly difficult when he tries to collaborate, as he must do, with educational authorities and religious workers Those who have had no practical experience of such associations should be able to see, from even a superficial acquaintance with some of the modern literature on social and psychological medicine and with some social workers, how delicate the position can sometimes be.)

If, as it should do, health education is to play a significant part in the attainment of bodily and mental health in the Tropics it is evident that investigations will have to be carried out to see how best to teach and how best to assess results. Such investigations cannot be carried out just as part of the routine work of an educationist or a public health officer; expert knowledge on social anthropology and on psychiatry is essential as well.

\section{A Growing Tendency}

With the growth of more representative Government in the British Colonial Empire there is a growing tendency for lay representatives and administrators to control, or at least influence, the direction of medical and public health affairs. The success of more lay control in health matters will depend very largely on the success that is obtained with the health education of the general public in practical matters and on the extent to which their representatives and leaders accept the teaching given and grasp the social and economic significance of the major diseases and the financial and administrative implications of their treatment and control.

Health information must be made available to lay administrators and councillors which will deal with current health problems as they present themselves year by year, with the economic and social repercussions of prevailing diseases, and with the practical measures that must be taken to improve medical facilities and raise standards of health

In preparing information of this kind it is essential that medical administrators should be placed in a position of 
sufficient independence to enable them to present facts and professional opinions regardless of their political or commercial implications.

As lay influence increases outside the departments it will provide some supervision of a kind that may be helpful, but not such as will meet departmental needs. Medical work expands comparatively rapidly in the Tropics, and supervision and assessment of work tend to lag behind the increasing routine executive work, with the result that the actual work of a department may grow to be at variance with the policy which it is expected to implement. To avoid this a closer linkage than exists at present is needed between executive and administrative staffs, and the latter must be given the time and facilities to keep in practical touch with all aspects of departmental work.

The services which have been outlined-the health education of the general population, the provision of special informatory facilities for lay administrators and councillors, and the extension of follow-up and inspectoral servicesare vital to British Colonial medicine, and, as a corollary, the administrators who will have to put them into effect will have to be trained for the task.

\section{Need for Special Training}

Whatever developments there may be in private practice in the Colonial Empire, there will always be a large volume of medical work which must be done by the health services of the central or local governments, and it should be recognized that special training should be made available for medical administrators. The duties of a station or district medical officer are, on a small scale, analogous to those of the head of a health service and his staff. Training in administration can therefore begin with the medical officer, who has sanitary, medico-legal, and general medical duties to perform.

Much of the medical work now needed in the Tropics, if it is to be productive, must be planned on a scale which requires several years for its completion, and medical officers should be encouraged to draw up their own schemes of work and to co-operate, within the framework of a general departmental policy, with other departments and organizations of related interests, especially education, agriculture, engineering, and such bodies as are concerned in social and moral welfare. It is not expected that every medical officer should operate a miniature medical department, but a selected proportion who show initiative, readiness to accept responsibility, and an aptitude for leadership and for administrative work generally should be given every opportunity, by way of study leave and conditions of work, to widen their knowledge not only of medicine itself but also of its relations with social and economic welfare.

In addition to the ordinary postgraduate courses which are available in tropical medicine, general medicine, public health, etc., there should be arrangements for selected candidates to be given special courses designed to provide the wider outlook which is now required in tropical social medicine. These should include the nutritional aspects of such agricultural subjects as soils and soil microbiology, fertilizers, animal feeding, dairy chemistry, storage of food crops, etc.; studies in education and sociology, comprising social psychology and educational psychology; and studies in psychiatry, including social psychiatry and mental hygiene. The medical officers should also, as opportunity permits, engage in some research, receiving guidance and criticism from an experienced research worker. Officers who continue to maintain those wider contacts for a long period obviously cannot specialize, or at least can do so only in a very narrow field. They should, nevertheless, so long as they maintain touch with clinical work, continue to be practical diagnosticians in such a way as will enable them to use and assess the services of specialists. This advanced general training prepares them for passing on from district, sanitary, or hospital work to take administrative charge of the health services of a county or province as the case may be. Another opening that should be available to them is hospital administration where the number of in-patients is large enough.

It is still debated whether the officer administering a hospital should be medically qualified or a layman. In Colonial medical administration there are great advantages in appointing a medical officer as administrator, provided he makes administration his primary duty, keeps touch (not as a consultant but as an administrator) with his officers. clinical work, and maintains with district work the contacts which make his hospital a unit in a larger team. He should be assisted by a lay administrator. Medical officers who receive the advanced training and have gained the special experience which has been outlined should be well equipped for the most senior administrative posts. These medical officers will be unable to keep their professional knowledge up to date unless they are provided with summaries for reference. These should be in the form of "digests" of what is known of the particular subjects at the time; they should not be précis of recent work. They could be compiled in loose-leaf form, and should show the latest state of knowledge, year by year, of the whole field of medicine. (An example of a reference book of the kind required for a particular subject, which is already available, is Martindale's Extra Pharmacopoeia.)

If medical administrators are to keep this close touch with their own and allied professions it is obvious that lay assistance of a first-class order must be developed to manage the details of lay administration within their department.

\section{Summary}

A short outline is given of medical administration and organization as it was in Tanganyika Territory before 1939 and in Trinidad and Tobago in 1947.

The advances made in the development of representative Government in the British Colonial Empire throw new responsibilities on medical departments, which should now accept it as one of their major functions to see that the representatives and leaders of the people are kept fully acquainted with the social and economic effects of the important prevailing diseases, the measures that can be taken to prevent or attenuate them, and the community discipline, in habits and behaviour, which is necessary for sound standards of health. Similarly, the medical departments must, as a long-range policy, play a major part in guiding the people themselves to a wholesome mode of living. These functions imply that there must be investigations-not necessarily by medical departments alone -into social structures and their inherent customs and practices.

Opportunities should be provided for medical officers of suitable calibre to engage both in work and in special duties which will equip them for supplying the directives and guidance which will be required of organized medical services. Medical administrators need more facilities for special studies than are now readily available for them. They must also have better facilities for the supervision and assessment of the work of their departments if the best results are to be obtained and misapplication and wastage of resources are to be avoided. As new and increasing demands are made on them because of the widening application of social medicine, as much as possible of routine non-professional administration must be delegated to laymen. 


\section{BIBLIOGRAPHY}

Annual Reports of the Medical Department, Tanganyika Territory, 1921-38.

Annual Reports of the Health Department, Trinidad and Tobago, $1945-7$.

Corson, J. F. (1932). Ann. trop. Med. Parasit., 26, 109.

(1935). J. trop. Med. Hyg., 38, 9.

Seheult, J. F. R. (1948). A Survey of the Trinidad Medical Service, 1814-1944. Government Printer, Trinidad and Tobago.

\section{A TRIAL OF PROCAINE PENICILLIN PREPARATIONS}

BY

\section{E. GRIFFITHS, F.R.C.S.}

A. J. WALKER, F.R.C.S.

(From the Surgical Professorial Unit, St. Bartholomew's Hospital)

AND

R. A. SHOOTER, M.D.

(From the Department of Bacteriology, St. Bartholomew's Hospital)

It now seems likely that for some time to come procaine penicillin will play an important part in penicillin therapy. The first paper describing its clinical use (Herrell, Nichols, and Heilman, 1947) advocated a dosage of 300,000 units in oil, this amount being contained in a total volume of $1 \mathrm{ml}$. Although a satisfactory clinical response was claimed with this dosage at the time, and by other authors subsequently, it has been criticized on the theoretical grounds that it would not provide throughout the whole of any 24-hour period detectable amounts of penicillin in the blood of all patients treated. Various preparations of procaine penicillin designed to overcome this drawback have been described, but as yet the majority of the reports have been mainly concerned with recording the blood levels obtained by their use.

This paper is an account of a trial of three preparations of procaine penicillin to determine whether any of them would satisfy the following criteria: (1) Provide a satisfactory preparation with which to treat acute staphylococcal infections of the skin and subcutaneous tissues, and, by analogy, infections due to more sensitive organisms. (2) Maintain detectable amounts of penicillin in the blood throughout 24 hours after a single injection. (3) Allow the dose to be given without difficulty in a volume of not more than $1 \mathrm{ml}$.

\section{Preliminary Trials}

Thomas, Lyons, Romansky, Rein, and Kitchen (1948) showed that the addition of aluminium stearate to procaine penicillin resulted in a slower release of penicillin from the site of injection and a consequent lengthening of the time during which penicillin could be found in the blood.

The first preparation tried by us consisted of 300,000 units of procaine penicillin in oil with $2 \%$ aluminium stearate contained in $1 \mathrm{ml}$., and this was used in the treatment of 24 patients with acute staphylococcal infections. This dose was given once every 48 hours, and penicillin was found in the blood of 22 of the patients after 24 hours and in the blood of 10 of the 11 patients tested after 48 hours. As reported previously, however (Griffiths,
Jones, Shooter, and Heady, 1949), the clinical response was not as satisfactory as that seen with 300,000 units of procaine penicillin. No attempt was made to use this preparation in daily doses or in larger amounts, as the immediate response in the first 24 hours of treatment was thought to be less satisfactory than with procaine penicillin and it was not desired to increase the volume of the injection above $1 \mathrm{ml}$.

A similar series of 41 patients was treated with daily injections of a mixture of 200,000 units of procaine penicillin in oil with $2 \%$ aluminium stearate and 100,000 units of sodium penicillin, again contained in $1 \mathrm{ml}$. With this preparation penicillin was found in the blood of only 29 out of the 38 patients tested at the end of 24 hours; and, as the clinical results compared unfavourably with those in patients treated with 300,000 units of procaine penicillin, this preparation also was discarded.

The third preparation tested consisted of a mixture containing 300,000 units of procaine penicillin in oil with $1 \%$ of aluminium stearate and 100,000 units of sodium penicillin contained in $1 \mathrm{ml}$. Initial clinical trials of this preparation were satisfactory. We have attempted to compare its action in the treatment of acute staphylococcal infections of the skin and subcutaneous tissues with that of 300,000 units of sodium penicillin in saline given twice daily, and 300,000 units of procaine penicillin given once daily, and records have been kept of penicillin levels in the blood throughout treatment.

\section{Methods of Treatment}

Patients were given an intramuscular injection of $1 \mathrm{ml}$. of the trial preparation, and this injection was repeated daily for five days. As local treatment, sodium sulphate $\left(12 \frac{1}{2} \%\right)$ and, in some cases, kaolin poultices were used, and immobilization of the affected part was advised whereever practicable. Only unavoidable and minimal incisions were made. Carbuncles were never incised. Most of the patients were examined at daily intervals, the remainder never less than once in three days. Clinical findings were recorded on a special form. As a rule a swab was taken from a lesion before the start of treatment or as soon as possible after pus had begun to discharge.

Conditions Treated.-Only out-patients with acute septic infections of the skin and subcutaneous tissues, mainly staphylococcal, who required penicillin were treated. The types of infection are given in Table $I$. Some of the

TABLE I.-Types of Infection Treated (113 Cases)

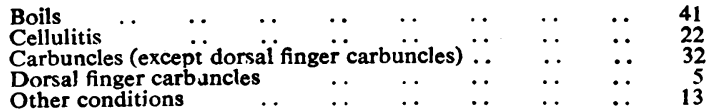

TABLE II

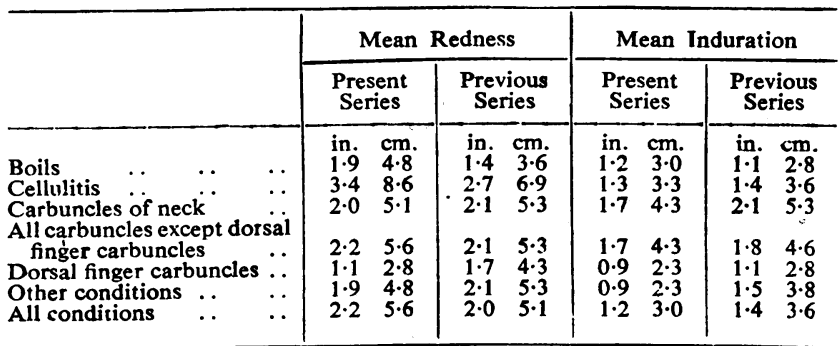

Present series $=$ Treatment with 300,000 units of procaine penicillin $+100,000$ units of sodium penicillin and $1 \%$ aluminium stearate. Previous series in Tables II and III = Combined procaine penicillin and sodium penicillin series taken from the paper by Griffiths. Jones, Shooter, and Heady (1949). 